\title{
Emotional Fitness and the Movement of Affective Science From Lab to Field
}

\author{
Sara B. Algoe and Barbara L. Fredrickson \\ Department of Psychology, University of North Carolina at Chapel Hill
}

\begin{abstract}
Emotions provide a ubiquitous and consequential backdrop to daily life, influencing everything from physiology to interpersonal relationships in the blink of an eye. Instances of emotional experience accumulate and compound to impact overall mental and physical health. Under optimal conditions, emotions are adaptive for the successful navigation of daily life. However, situational features of military life likely amplify everyday emotions and their impact, creating the need for soldiers to have a well-oiled emotional resilience system in place from the start, to be maintained throughout their careers. Basic research in affective science has identified the active ingredients that would be required in order for such a system of skills and abilities to have maximum impact on overall emotional fitness. Results of this emotional resilience training may provide compounding benefits for the individual as well as have spreading impact for the benefit of the military unit and other social connections. The Comprehensive Soldier Fitness initiative highlights important new frontiers in affective science and presents a challenge to our field that requires taking a second look at the theory-testing process.
\end{abstract}

\section{Keywords}

positive emotions; resilience; social functions of emotions; chronic stress; emotional fitness

Emotions, whether anticipated, felt in the moment, or recalled, shape our thoughts, motivations, and behaviors from morning until night, every day of our lives. This includes everything from deciding to take the long route to work to avoid the dense traffic that got you so agitated the last time you tried the "short" route, to sharing a laugh with a friend to ease the tension before an important meeting, to deciding whether to linger for dessert at the end of a first date. These mundane examples demonstrate the relevance of emotions to all human beings: Emotions provide a ubiquitous backdrop to our everyday experience.

Yet, beyond their ubiquity, emotions are important in everyday life: When experienced in reaction to an event, the emotion itself acts as a coordinated response to that situation, which momentarily draws together cognitive, biological, and behavioral resources and deploys them in ways that reflect personal and ancestral histories. This response recurs multiple times within each day, and under optimal conditions, emotional reactions facilitate the smooth navigation of everyday life (see Keltner \& Gross, 1999). For example, anger might help one know it is time to face up to an interpersonal conflict, whereas gratitude might identify an opportunity to connect with a caring interaction partner. Under nonoptimal

(C) 2011 American Psychological Association

Correspondence concerning this article should be addressed to Sara B. Algoe, Department of Psychology, CB \#3270 Davie Hall, University of North Carolina, Chapel Hill, NC 27510. algoe@unc.edu.

Full disclosure of interests: Sara B. Algoe was paid consulting fees to develop the online training modules for the Comprehensive Soldier Fitness program that are mentioned in this article. 
conditions, however, negative emotions can get under the skin and stay there, whereas positive emotions can seem hard to come by. More generally, people's momentary emotions accumulate and compound and ultimately contribute to their overall mental and physical health: Each emotional experience lays down tracks for the next and can trigger either downward or upward spirals. For all people, then, understanding the role of emotions in daily life can help them effectively navigate bad times and capitalize on good times, with long-term consequences for well-being.

When it comes to the military context, this prescription to understand emotions warrants careful adherence. What we hear in the news is repeated in empirical research: scores of servicemen and women coming back from Afghanistan or Iraq with mental health problems, low willingness to seek treatment, and attrition from service (e.g., Hoge, Auchterlonie, \& Milliken, 2006), along with the potential for spreading impact of such mental disruption (e.g., posttraumatic stress disorder, or PTSD) for the health and well-being of military family members (e.g., Marshall, Panuzio, \& Taft, 2005).

Yet, even before deployment, the military context provides unique circumstances that likely amplify everyday emotions and their impact. To cite just a few examples, joining the military leads to a changed social structure from one of relative independence to one of tight interdependence and strict hierarchy; friends and family are left behind as servicemen and women move from one post to another; and, particularly given the current conflicts in Afghanistan and Iraq, many face the constant possibility of deployment. Key aspects of these circumstances, such as lack of control or loss of social networks, have long been identified as factors that contribute to depression (e.g., Barnett \& Gotlib, 1988; Ross \& Mirowsky, 1989). In general, periods of chronic strain are difficult to manage for even the most emotionally savvy or resilient individuals. Even so, some people are resilient, even within the challenging institutional structure of the military (Lukey \& Tepe, 2008). What if emotional resilience could be taught?

There is reason to believe it can: The past 30 years of basic research on emotions have revealed core components that could well comprise the foundation of a training program aimed at promoting emotional fitness through the cultivation of emotions-based knowledge and skills. Of course, there are obstacles to overcome. We will come back to those. But let us begin with what is known.

\section{Empirical Foundation}

It almost goes without saying that serious consideration of a preventive emotional resilience training program would not be possible had it not been for the great strides made in developing therapeutic programs to help people cope with emotions-based mental disorders such as anxiety, depression, and PTSD. From these evidence-based strategies for treating clinical populations, as well as from related basic research within nonclinical populations, have come a variety of tools that are now available to help people recover from mental illness and respond adaptively to momentary negative emotional events in everyday life. To mention just two examples, cognitive-behavioral therapy (A. T. Beck, 1979; J. S. Beck, 1995 ) and its newer offshoot, mindfulness-based cognitive therapy (Segal, Williams, \& Teasdale, 2002), are both fully compatible with the contemporary emotion science view that emotions stem from people's interpretations of their current circumstances, and each therapeutic approach has garnered an impressive empirical track record in interventions at the level of these cognitive appraisals (see Reivich \& Seligman, 2011, this issue). Overall, the cumulative impact of using these tools alone may help to alleviate distress and improve both mental and physical health in military contexts. Yet relief from distress addresses only half the emotional spectrum. In fact, we know that in the everyday lives of those not in the 
military, experiences of positive emotions are more frequent than negative emotions (Fredrickson \& Losada, 2005). We have every reason to suspect that soldiers experience positive emotions too, and like others, when circumstances allow, they too could learn to self-generate positive emotions more frequently. Why might this matter?

For more than a decade, Fredrickson and colleagues have been advancing the broaden-andbuild theory of positive emotions together with scientific evidence to support it. Their work suggests that, in addition to being an antidote to negative emotional arousal (Fredrickson \& Levenson, 1998), positive emotions contribute importantly to health and well-being (Fredrickson, 1998; Fredrickson, Cohn, Coffey, Pek, \& Finkel, 2008). Unlike negative emotions, which arise in response to threats and undesired circumstances and draw attention to problems that require immediate attention, positive emotions identify opportunities that have arisen in the environment. In contrast to the narrowed attentional focus characteristic of negative emotions, positive emotions momentarily broaden people's cognitive and perceptual capacities (Fredrickson \& Branigan, 2005; Schmitz, De Rosa, \& Anderson, 2009; Wadlinger \& Isaacowitz, 2006). The more expansive awareness characteristic of positive emotions makes it easier to build durable personal resources. Indeed, recent experimental evidence demonstrated that working adults who learned to self-generate sincere and contextually appropriate positive emotions triggered increases in their own personal and social resources such as purpose in life and social support; in turn, these increased resources led to reduced symptoms of depression and increased satisfaction with life (Fredrickson et al., 2008). Such durable resources may be drawn on in times when people need them most. For example, prospective evidence shows that in times of stress, experiences of positive emotions appear to promote effective coping (Folkman \& Moskowitz, 2000; Fredrickson, Tugade, Waugh, \& Larkin, 2003) and reduce mortality (Moskowitz, 2003), independent of the damaging effects of negative emotions experienced during those same stressful times.

The science of emotions thus suggests that, in addition to reducing the frequency and duration of negative emotional experiences, for optimal mental and physical health, attention must also be paid to increasing the frequency and duration of positive emotional experiences. Indeed, Fredrickson and Losada (2005) argued that optimal ratios of positive to negative emotions reside above $3: 1$. Though problems may occur if positivity ratios exceed about 11:1, it is also important to note that the 1 in the denominator prompts the conclusion that negative emotions are necessary for human flourishing (Fredrickson \& Losada, 2005). Viewed from this perspective, negative emotions need not be eliminated, especially when they are contextually appropriate: The prescribed 3:1 ratio is flexible enough to encompass the full range of human emotional experience.

In fact, the 3 in the numerator truly suggests the importance of experiencing a range of positive emotional experiences in a given day. Fortunately, recent years have brought advances in scientific understanding of a range of distinct positive emotions. Indeed, though the broaden-and-build theory highlights unique properties of an entire class of emotions (i.e., the ones accompanied by a pleasant subjective feeling), in line with other functionalist approaches to emotions (e.g., Keltner \& Gross, 1999; Tooby \& Cosmides, 1990), it rests on the assumption that any specific emotion (e.g., pride, gratitude, or amusement) evolved as an adaptive solution to a specific type of situation that recurred across millennia. That is, distinct positive emotions help people take advantage of distinct opportunities that come along in everyday life, as evidence from multiple research labs has borne out over the past few years (for a review, see Algoe, Fredrickson, \& Chow, in press). For example, evidence suggests functional distinctions among the "other-praising" positive emotions of admiration, moral elevation, and gratitude that arise in response to another's display of remarkable skill, moral virtue, or attention to one's personal needs and preferences, respectively (Algoe \& Haidt, 2009). In turn, each emotion may principally build distinct personal and social 
resources. For example, of these three positive emotions, Algoe and colleagues have posited that the emotion of gratitude serves to find, remind, and bind people to caring individuals in their lives (Algoe, Haidt, \& Gable, 2008): Compared with other specific positive emotions, gratitude's specialty is promoting high-quality relationships. Indeed, prospective data from both members of ongoing relationships (that is, the grateful recipient and the attentive benefactor) support this hypothesis, in friendships (Algoe et al., 2008) as well as in romantic relationships (Algoe, Gable, \& Maisel, 2010). With this emerging understanding of the distinct forms and functions of distinct positive emotions, basic researchers are discovering the active ingredients that may well combine to contribute to emotional health and wellbeing. Ultimately, capitalizing on a variety of momentary opportunities should add breadth to one's repertoire of personal resources, enhancing the likelihood of having the appropriate tool at the right time, being able to cope with what life puts in one's way, and seizing (or creating) opportunities for personal growth whenever possible. Even so, evidence suggests that most people fall short of the 3:1 ratio (Fredrickson \& Losada, 2005) and would therefore benefit from learning to self-generate a range of distinct positive emotions in daily life.

Research already documents that people who are particularly adept at self-generating positive emotions are more likely to be resilient (Tugade \& Fredrickson, 2004). To be resilient means to bend without breaking and to quickly rebound from adversity. Complementary evidence suggests that resilient outcomes after traumatic events are far more common than previously suspected (Bonanno, 2004), reflecting the "ordinary magic" of basic human adaptive systems such as those involving emotions (Masten, 2001). Masten suggested that, as long as a person's given basic system (e.g., emotions-based system) is in good working order, the person can handle adversity. However, impairment to the system causes risks to resilient outcomes, "particularly if the environmental hazards are prolonged" (Masten, 2001, p. 227), as they are in the military context. Importantly, evidence exists linking the adaptive deployment of emotions with the outcome of resilience. For example, self-generated positive emotions are an independent active ingredient in the rebound process (Fredrickson et al., 2003; Ong, Bergeman, Bisconti, \& Wallace, 2006; Tugade \& Fredrickson, 2004), and prospective evidence shows that, over time, daily experiences of positive emotions build enduring resilience and thereby contribute to increases in global mental health (Cohn \& Fredrickson, 2010). Moreover, brain research identifies resilient individuals as emotionally nimble, appropriately reactive to negative events, but less likely to worry about uncertainties and quick to shake off threats that do not materialize (Waugh, Wager, Fredrickson, Noll, \& Taylor, 2008). Overall, evidence suggests a particular set of emotions-based skills and abilities that collectively comprise the adaptive deployment of emotions in everyday life; we call this the emotional resilience system. Below, we describe the skills and abilities of a soldier who uses this system well, that is, an emotionally resilient soldier.

Finally, though this review has primarily emphasized the individual, when considering the role of emotions within the military context it is especially relevant to note that emotions evolved within the context of group living. Not only are emotions most often caused by the real or imagined presence of others, but emotions have impact beyond the self: The experience and expression of emotion influences an interaction partner and can also be taken as information by incidental witnesses. Research on the other-praising emotions, for instance, suggests that the verbal and nonverbal signals that emanate from these emotions may help to spread good reputations throughout a society (Algoe \& Haidt, 2009). We speculate that helping soldiers cultivate emotions-based skills and virtues may even have the incidental benefit of spreading a positive reputation of the United States abroad. Moreover, recent work on emotional contagion shows that positive emotions spread through social networks, and researchers have concluded that happiness "is a collective phenomenon" 
(Fowler \& Christakis, 2008, p. 23). The implications of this perspective for the military bear stating: Within tightly knit social units, the emotional fitness of each member also becomes the responsibility of other members within the group. To the extent that positive emotions build durable and collective resources, leaders who provide soldiers with emotionsbased skills training could well provide compounding benefits for military units across multiple domains, as reviewed below (see also Hannah \& Lester, 2009).

\section{Emotional Fitness Training in the Military What Might an Emotionally Resilient Soldier Look Like?}

We suggest that an emotionally resilient soldier has agility, deftly navigating the emotional slings and arrows of daily military life, quickly capitalizing on opportunities for growth as they arise, creatively finding new ways to self-generate personal growth, and often being able to find at least some good, even while acknowledging the contexts of difficult life circumstances that may surround him or her. In short, emotional resilience requires a rich emotional vocabulary as well as the skills and ability to decrease the frequency and duration of negative emotions and increase the frequency and duration of genuine and contextually appropriate positive emotions in everyday life.

\section{What Are the Products of Emotional Resilience?}

An emotional fitness training course cannot eliminate mental health problems from the population nor the need for their treatment. However, evidence from the literature we have reviewed suggests that assessment should focus on the following types of outcomes for people who improve their emotional resilience, as defined above: more flexible responding in the face of threat, better problem-solving skills, faster wound healing, greater empathic accuracy, better interpersonal relationships, increased meaning in life, increased success, increased wealth, decreased mental illness, increased mental health, increased physical health, and longer lives (e.g., for relevant reviews, see Brown, Ryan, \& Creswell, 2007; Lyubomirsky, King, \& Diener, 2005; Pressman \& Cohen, 2005; see also, Robles, Brooks, \& Pressman, 2009). And those are just the personal benefits. Imagine the potential positive consequences of increased emotional resilience for a buddy, subordinate, or leader as well as for the unit, communities within which soldiers live, and even for taxpayer dollars.

\section{What Will It Take to Cultivate Emotionally Resilient Soldiers?}

Given that moments of emotion, experienced in everyday life, lay the foundation for the broad spectrum of benefits anticipated from emotional fitness training, "moments" are the target of the training we envision. Of key consideration for optimal training is that emotions spring up throughout the day, every day. Emotional fitness requires agility within the broad variety of emotional moments of everyday life. Just like physical fitness, true emotional fitness will require training, practice, and maintenance (Loehr \& Schwartz, 2003). Athletes refine their techniques and then practice them until they become second nature. Moreover, to be physically fit requires a range of skills, for example, speed, strength, endurance, and flexibility. Each of those skills involves a more complex base, for example, each individual muscle needs to be built to have a strong body. The analogy is clear: Overall emotional fitness will require learning techniques to build a range of skills, and all of these skills should be practiced regularly in order to become habits of the mind. Indeed, the science behind neuroplasticity suggests that, as new emotional skills are developed and practiced, they become reinforced by brain changes, as neurons that "fire together, wire together" (e.g., Doidge, 2007). Other emotions-based mind-training programs in nonmilitary populations work from this principle, requiring daily practice over the course of weeks before global changes accrue (e.g., Fredrickson et al., 2008); no evidence suggests soldiers' mental habits will form or produce such benefits more quickly. Training and practice will be key. 
That being said, there are three primary phases of training required for successful integration of these skills and abilities into soldiers' mental habits. Resting on the literature reviewed above, the full scope of this program was informed by a meeting between a panel of emotions experts from across psychological disciplines and representatives from the U.S. Army's Comprehensive Soldier Fitness (CSF) program, held in June 2009 at the University of North Carolina at Chapel Hill. ${ }^{1}$ Here, we briefly describe each phase of training:

Phase I: Basic training-To truly tackle the goal of building durable skills, a solid foundation must be laid. One obvious requirement, particularly in the tough context of the military, is to break through barriers to taking advantage of one's emotional resilience system by dispelling myths (e.g., emotions are not "soft" or to be ignored, but are functional and adaptive) and increasing understanding of the role that emotions play in everyday life. One way to accomplish this is to get soldiers to identify with concrete and mundane ways that emotions influence their lives, such as the examples used in the opening paragraph of this article.

Additional to appropriately framing the concept of "emotions" is the more active component of basic training: Just as they must learn all the working parts of their weapons before mastering them, soldiers must learn all the working parts of emotions. Soldiers must understand when they are experiencing an emotion (Lane \& Schwartz, 1987) as well as its consequences: Emotions affect body, mind, and social connections. Negative emotions such as anger and fear are adaptive in certain times and places, whereas positive emotions such as gratitude and pride are adaptive in others (for a review, see Algoe et al., in press), and it is important to attend to the full emotional spectrum. Through increased emotional granularity (e.g., Feldman, 1995) and affect labeling (Lieberman et al., 2007), soldiers will learn what emotions reveal about themselves and others. Simultaneously, the increased ability to identify patterns of gratuitous negativity and to discover opportunities to cultivate genuine positivity is congruous with the goal of building global emotional well-being. Phase I provides the training that will allow soldiers to troubleshoot and to keep their emotional resilience systems in good working order once the training is over and they are on their own. Moreover, it provides the building blocks from which the rest of the training will grow. Thus, directly in line with the goals of CSF, Phase I empowers soldiers to become active participants in their own emotional lives.

Phase II: Emotion regulation-Though emotion regulation seems like the most essential part of an emotional fitness training program, we foresee a diminished impact on global emotional well-being unless Phase II rests on the foundation established in Phase I. The obvious reason is that learning how to regulate emotions works best once one is able to identify the source and impact of an emotion. There is another reason, however, that is central to why and how this approach, as a preventive emotional wellness training program, represents a paradigm shift: Active regulation of genuine positive emotions is at least as important to emotional resilience as regulation of negative emotions. Phase I lays the foundation that is critical to the success of this approach.

On the whole, soldiers will not be coming to this training seeking a therapeutic intervention to cope with mood disorders that are already present. Rather, the majority of people who come to this program will share many characteristics of many readers of this article: They have everyday stressors and may feel like they are of "normal" mental health, yet they would not be opposed to finding ways to increase their happiness and success. Thus, the

\footnotetext{
${ }^{1}$ In addition to ourselves, meeting attendees included Sean Hannah, Deborah Jones, Anthony Mancini, Laura McKee, Jeffrey Moore, Rhonda Cornum, and Richard Gonzales. We appreciated the opportunity to have this open exchange of ideas and gratefully acknowledge the insights gleaned from that productive meeting.
} 
goal of the emotion regulation phase of training is not merely to focus on the skills and abilities from the emotional resilience system that can help people cope with cognitions central to mood disorders and emotional problems. Rather, the goal is to teach the full range of skills and abilities that contribute to the "ordinary magic" that comes from a wellfunctioning emotional resilience system, as reviewed above. With practice, these techniques will become habits of the mind, to be used as needed. Ultimately, soldiers would learn specific tools and techniques to approach an optimal 3:1 "positivity ratio" in everyday life by reducing the frequency and duration of negative emotions while increasing the frequency and duration of positive emotions such as admiration, gratitude, love, amusement, and pride.

\section{Phase III: Optimizing the emotional landscape for self and others-The third} phase of training, though brief, is what maximizes the impact of the entire emotional fitness endeavor. Though Phase II will teach a wide range of emotion regulation skills and abilities, soldiers will require help in finding ways and motivation to practice these skills once the training ends. In the same way that health behaviors are best implemented through channel factors such as action plans (Leventhal, Singer, \& Jones, 1965), soldiers will create their own channel factors in everyday life to optimize their emotional landscape. This includes finding positive-emotion self-interventions that provide the best fit to personality (see Lyubomirsky, 2008; Sin \& Lyubomirsky, 2009) as well as deciding on ways to avoid gratuitous negativity and its pernicious effects (e.g., Gilbert, Lieberman, Morewedge, \& Wilson, 2004). These are the final tools the soldier will need for his or her own improvement.

Yet the impact of emotions is not limited to the self. This last phase of training maximizes the impact of emotional resilience for the collective: for the functioning of the military unit, family units, and the communities within which the soldiers live. The final steps of primary training would thus focus on empathic accuracy, setting up optimal emotional environments for others (e.g., Dutton, Worline, Frost, \& Lilius, 2006), and communication of emotion (e.g., Algoe, Fredrickson, Gable, \& Strachman, 2011). To the extent that the social unit functions at multiple levels (for elaboration, see Cacioppo, Reis, \& Zautra, 2011, this issue) and happiness truly is a collective phenomenon (Fowler \& Christakis, 2008), emotional fitness training will only be complete and provide optimal results if the training extends beyond consideration of the self.

\section{Getting it Done}

Now comes the hard part. To date, the CSF program has implemented only a small fraction of this training, using online modules, and so we look with cautious optimism to the future. As a whole, the emotional fitness training program is geared toward the masses, focusing on the skills and abilities that comprise and facilitate the emotional resilience system. As such, it has something to offer soldiers at all levels of emotional well-being. However, we see two key areas that would benefit from more focused attention by the Army.

First, we believe the CSF program has a real challenge in addressing the needs of people who are struggling emotionally. Upon taking the Global Assessment Tool (GAT; see Peterson, Park, \& Castro, 2011, this issue), this group will have voluntarily endorsed items indicating their poor mental health status. First, these individuals will likely be immediately ready for strategies to cope that are tailored to a clinical population; indeed, they should not wait to get a version of emotions-based training. In addition, the manner in which these modules are set up provides the Army a unique opportunity to deliver a specialized set of training to work as a temporary adjunct to appropriate clinical treatment. Given that the soldiers may take the GAT from any location, access to a clinician to set up treatment in person may prove to be difficult; moreover, there is often a stigma attached to seeking 
treatment. However, a set of online modules that uses the best-known strategies for intervention with clinical populations may provide temporary exercises and relief while illuminating the path toward appropriate treatment (e.g., through listing of resources and options for treatment).

Second, for those high in emotional well-being who have already gone through the full course, there is a real opportunity: Emotions-based skills and abilities are critical to successful interactions with others, such as in negotiation, strategy, and leadership. Understanding how emotions influence others' judgments and decisions as well as their success and productivity in the work environment are all additional skills: Additional modules could easily build on the proposed training to teach these tools for success and leadership to those who would benefit. In sum, we see the potential for emotional fitness training to truly adhere to that old Army slogan for soldiers to "Be all you can be." By giving soldiers a program of emotional fitness training, CSF stands to help individual soldiers, the Army as a whole, as well as society.

Though each component of the proposed training program draws from basic empirical research, there is no existing empirical evidence that the program we envision will do what theory suggests, particularly in a military population. Rigorously testing the efficacy of such training, using tightly controlled experimental designs, is the first and foremost requirement. This work is under way. At the time of writing the manuscript for this article, the first author is preparing to implement a full version of this training program as part of a randomizedcontrolled trial in collaboration with Amishi Jha. Similar to prior studies (Jha, Stanley, Kiyonaga, Wong, \& Gelfand, 2010), the training will be delivered live (i.e., face-to-face) to soldiers predeployment; the proposed course will be compared with mindfulness-based training for soldiers (Stanley \& Jha, 2009). As this necessary translational research is carried out, it will also be critical to test theorized psychological mechanisms for short-term gains, as well as whether the tested training programs teach durable skills with lasting impact. Finally, in time, it will be vital to determine what the minimally sufficient dose of training may be. In short, the CSF initiative could open as many opportunities for theory testing as for application.

\section{What Does Comprehensive Soldier Fitness Have to Offer Affective Scientists?}

We see the CSF program as a remarkable opportunity for our field. At one level is the obvious vision: This is an opportunity to bring the fruits of our best science directly to the lives of more people than would otherwise be possible. Moreover, given its scope, if successful, these training programs could serve as models for other mental health initiatives across the nation, in educational, medical, and community settings. At yet another level, this is a tremendous opportunity for affective scientists to pause and take stock of the potential, as well as the limits, of their theories. The past 30 years of emotions research have brought significant advances in emotion theory that provide the active ingredients for the current training vision. We invite you to consider what may be missing or necessary for the next frontier.

From our perspective, the CSF initiative has brought to full relief that our science is ready to start pushing old theories and creating new ones by moving basic research from the lab to the field. Of course, one-time manipulations in the lab, focused on an individual's own outcome, are important steps in the theory-testing process. Yet, without ultimately knowing whether and how hypothesized emotional mechanisms play out in the context of daily lifeand in the very stressful daily lives of soldiers- ours remains a science that is stalled out in the laboratory, with the implications of our important discoveries remaining mere thought 
exercises (see also Lewin, 1951). What if physicists had stayed in the lab rather than testing their theories in nature? We too must be sure that our theories are not overturned in context. Given the major advances in technology, methodology, and statistical acumen in just the past decade, the answers to questions about the role of emotions in context are not beyond the reach of even the most hard-nosed scientist among us.

Moreover, the military context highlights at least two structural elements of everyday life in which more basic emotions research is required, and a military field setting may be one of the best contexts in which to study it and advance emotion theory. One is chronic stress, which is arguably a normative part of human experience (e.g., chronic illness, loss of job, divorce, final examinations; see Lazarus \& Folkman, 1984) and is just the type of situation to put people most at risk for changes in mental health status. Yet research on emotions has relatively little to say about the role of emotions (and their mechanics) within these phases of life in which situational factors impose cumulative strain (some exceptions include Moskowitz, 2003; Stanton et al., 2000; Zautra, Smith, Affleck, \& Tennen, 2001). For example, do early stressors inoculate against the effects of later stressors? What is the role of emotional expression in the midst of such phases? Do momentary positive emotions improve problem solving even here?

The second structural element of everyday life that is amplified in the military context yet relatively neglected by our science is that we are an interdependent species. Examining the social consequences of emotions as they are transmitted from one person to the next, ripple through the network, and potentially contribute to a collective resilience is appealing for both theoretical and practical reasons. Nearly 10 years of fighting two wars has exacerbated the chronic stress normally associated with military life as well as the need for unit members to draw strength from each other. In addition to the intervention itself, this population is ready for the scientific spotlight that accompanies a program like CSF.

Moving basic research from the lab to the field, as we see it, is theory testing at its most challenging. Yet, to the extent that our field addresses questions that are relevant to the very real conditions under which emotions happen in everyday life as well as the true impact they have for soldiers, the military unit, and society, it has the potential to be a mutually beneficial arrangement. By initiating CSF, the Army has posed a challenge to our field. The challenge cannot be answered by one research lab producing a "magic bullet." Many questions remain at all levels of analysis, from basic to applied, and this will require a collective effort. For success, researchers from across the discipline must first take the challenge seriously and then take a close look at their own work through a new lens. How might your work be relevant to this challenge? What are the relevant knowledge gaps in your domain of expertise? Which theories are begging to be put to the test in everyday and military contexts? By taking up CSF's challenge, our field has the opportunity to address a serious societal concern while simultaneously advancing the scope of our science.

\section{References}

Algoe, SB.; Fredrickson, BL.; Chow, S-M. Emotions research. In: Sheldon, KM.; Kashdan, TB.; Steger, MF., editors. Designing the future of positive psychology: Taking stock and moving forward. New York, NY: Oxford University Press; (in press)

Algoe, SB.; Fredrickson, BL.; Gable, SL.; Strachman, A. Beyond “Thanks!”: High-quality expressions of appreciation strengthen relationships. 2011. Manuscript submitted for publication

Algoe SB, Gable SL, Maisel NC. It's the little things: Everyday gratitude as a booster shot for romantic relationships. Personal Relationships. 2010; 17:217-233.10.1111/j.

1475-6811.2010.01273.x

Am Psychol. Author manuscript; available in PMC 2011 August 15. 
Algoe SB, Haidt J. Witnessing excellence in action: The "other-praising" emotions of elevation, gratitude, and admiration. Journal of Positive Psychology. 2009; 4:105127.10.1080/17439760802650519 [PubMed: 19495425]

Algoe SB, Haidt J, Gable SL. Beyond reciprocity: Gratitude and relationships in everyday life. Emotion. 2008; 8:425-429.10.1037/1528-3542.8.3.425 [PubMed: 18540759]

Barnett PA, Gotlib IH. Psychosocial functioning and depression: Distinguishing among antecedents, concomitants, and consequences. Psychological Bulletin. 1988; 104:97126.10.1037/0033-2909.104.1.97 [PubMed: 3043529]

Beck, AT. Cognitive therapy and the emotional disorders. New York, NY: Meridian; 1979.

Beck, JS. Cognitive therapy: Basics and beyond. New York, NY: Guilford Press; 1995.

Bonanno GA. Loss, trauma, and human resilience: Have we underestimated the human capacity to thrive after extremely aversive events? American Psychologist. 2004; 59:2028.10.1037/0003-066X.59.1.20 [PubMed: 14736317]

Brown KW, Ryan RM, Creswell JD. Mindfulness: Theoretical foundations and evidence for its salutary effects. Psychological Inquiry. 2007; 18:211-237.10.1080/10478400701598298

Cacioppo JT, Reis HT, Zautra AJ. Social resilience: The value of social fitness with an application to the military. American Psychologist. 2011; 66:43-51.10.1037/a0021419 [PubMed: 21219047]

Cohn MA, Fredrickson BL. In search of durable positive psychology interventions: Predictors and consequences of long-term positive behavior change. Journal of Positive Psychology. 2010; 5:355-366.10.1080/17439760.2010.508883 [PubMed: 21709728]

Doidge, N. The brain that changes itself. New York, NY: Penguin; 2007.

Dutton JE, Worline MC, Frost PJ, Lilius J. Explaining compassion organizing. Administrative Science Quarterly. 2006; 51:59-96.

Feldman LA. Valence focus and arousal focus: Individual differences in the structure of affective experience. Journal of Personality and Social Psychology. 1995; 69:153166.10.1037/0022-3514.69.1.153

Folkman S, Moskowitz JT. Stress, positive emotion, and coping. Current Directions in Psychological Science. 2000; 9:115-118.10.1111/1467-8721.00073

Fowler JH, Christakis NA. Dynamic spread of happiness in a large social network: Longitudinal analysis over 20 years in the Framingham Heart Study. British Medical Journal. 2008 Advance online publication. 10.1136/bmj.a2338

Fredrickson BL. What good are positive emotions? Review of General Psychology. 1998; 2:300 319.10.1037/1089-2680.2.3.300

Fredrickson BL, Branigan C. Positive emotions broaden the scope of attention and thought-action repertoires. Cognition \& Emotion. 2005; 19:313-332.10.1080/02699930441000238

Fredrickson BL, Cohn MA, Coffey KA, Pek J, Finkel SM. Open hearts build lives: Positive emotions, induced through loving-kindness meditation, build consequential personal resources. Journal of Personality and Social Psychology. 2008; 95:1045-1062.10.1037/a0013262 [PubMed: 18954193]

Fredrickson BL, Levenson RW. Positive emotions speed recovery from the cardiovascular sequelae of negative emotions. Cognition and Emotion. 1998; 12:191-220.10.1080/026999398379718

Fredrickson BL, Losada M. Positive emotions and the complex dynamics of human flourishing. American Psychologist. 2005; 60:678-686.10.1037/0003-066X.60.7.678 [PubMed: 16221001]

Fredrickson BL, Tugade MM, Waugh CE, Larkin GR. What good are positive emotions in crisis? A prospective study of resilience and emotions following the terrorist attacks on the United States on September 11th, 2001. Journal of Personality \& Social Psychology. 2003; 84:365376.10.1037/0022-3514.84.2.365 [PubMed: 12585810]

Gilbert DT, Lieberman MD, Morewedge CK, Wilson TD. The peculiar longevity of things not so bad. Psychological Science. 2004; 15:14-19.10.1111/j.0963-7214.2004.015001003.x [PubMed: 14717826]

Hannah ST, Lester PB. A multilevel approach to building and leading learning organizations. The Leadership Quarterly. 2009; 20:34-48.10.1016/j.leaqua.2008.11.003 
Hoge CW, Auchterlonie JL, Milliken CS. Mental health problems, use of mental health services, and attrition from military service after returning from deployment to Iraq or Afghanistan. Journal of the American Medical Association. 2006; 295:1023-1032. [PubMed: 16507803]

Jha AP, Stanley EA, Kiyonaga A, Wong L, Gelfand L. Examining the protective effects of mindfulness training on working memory and affective experience. Emotion. 2010; 10(1):5464.10.1037/a0018438 [PubMed: 20141302]

Keltner D, Gross JJ. Functional accounts of emotions. Cognition \& Emotion. 1999; 13:467_ 480.10.1080/026999399379140

Lane RD, Schwartz GE. Levels of emotional awareness: A cognitive-developmental theory and its applications to psychopathology. American Journal of Psychiatry. 1987; 144:133-143. [PubMed: 3812780]

Lazarus, RS.; Folkman, S. Stress, appraisal, \& coping. New York, NY: Springer; 1984.

Leventhal H, Singer RP, Jones S. Effects of fear and specificity of recommendations upon attitudes and behavior. Journal of Personality and Social Psychology. 1965; 2:20-29.10.1037/h0022089 [PubMed: 14313839]

Lewin, K. Field theory in social science; selected theoretical papers. Cartwright, D., editor. New York, NY: Harper \& Row; 1951.

Lieberman MD, Eisenberger NI, Crockett MJ, Tom SM, Pfeifer JH, Way BM. Putting feelings into words: Affect labeling disrupts amygdala activity in response to affective stimuli. Psychological Science. 2007; 18:421-428.10.1111/j.1467-9280.2007.01916.x [PubMed: 17576282]

Loehr, J.; Schwartz, T. The power of full engagement. New York, NY: Free Press; 2003.

Lukey, BJ.; Tepe, V., editors. Biobehavioral resilience to stress. Boca Raton, FL: CRC Press, Taylor \& Francis Group; 2008.

Lyubomirsky, S. The how of happiness: A scientific approach to getting the life you want. New York, NY: Penguin Press; 2008.

Lyubomirsky S, King L, Diener E. The benefits of frequent positive affect: Does happiness lead to success? Psychological Bulletin. 2005; 131:803-855.10.1037/0033-2909.131.6.803 [PubMed: 16351326]

Marshall AD, Panuzio J, Taft CT. Intimate partner violence among military veterans and active duty servicemen. Clinical Psychology Review. 2005; 25:862-876.10.1016/j.cpr.2005.05.009 [PubMed: 16006025]

Masten AS. Ordinary magic: Resilience processes in development. American Psychologist. 2001; 56:227-238.10.1037/0003-066X.56.3.227 [PubMed: 11315249]

Moskowitz JT. Positive affect predicts lower risk of AIDS mortality. Psychosomatic Medicine. 2003; 65:620-626.10.1097/01.PSY.0000073873.74829.23 [PubMed: 12883113]

Ong AD, Bergeman CS, Bisconti TL, Wallace KA. Psychological resilience, positive emotions, and successful adaptation to stress in later life. Journal of Personality and Social Psychology. 2006; 91:730-749.10.1037/0022-3514.91.4.730 [PubMed: 17014296]

Peterson C, Park N, Castro CA. Assessment for the U.S. Army Comprehensive Soldier Fitness program: The Global Assessment Tool. American Psychologist. 2011; 66:10-18.10.1037/ a0021658 [PubMed: 21219043]

Pressman SD, Cohen S. Does positive affect influence health? Psychological Bulletin. 2005; 131:925971. [PubMed: 16351329]

Reivich K, Seligman MEP, McBride S. Master resilience training in the U.S. Army. American Psychologist. 2011; 66:25-34.10.1037/a0021897 [PubMed: 21219045]

Robles TF, Brooks KP, Pressman SD. Trait positive affect buffers the effects of acute stress on skin barrier recovery. Health Psychology. 2009; 28:373-378.10.1037/a0014662 [PubMed: 19450044]

Ross CE, Mirowsky J. Explaining the social patterns of depression: Control and problem solving-or support and talking? Journal of Health \& Social Behavior. 1989; 30:206-219.10.2307/2137014 [PubMed: 2738367]

Schmitz TW, De Rosa E, Anderson AK. Opposing influences of affective state valence on visual cortical encoding. Journal of Neuroscience. 2009; 29:7199-7207.10.1523/JNEUROSCI. 5387-08.2009 [PubMed: 19494142] 
Segal, ZV.; Williams, JMG.; Teasdale, JD. Mindfulness-based cognitive therapy for depression. New York, NY: Guilford Press; 2002.

Sin NL, Lyubomirsky S. Enhancing well-being and alleviating depressive symptoms with positive psychology interventions: A practice-friendly meta-analysis. Journal of Clinical Psychology: In Session. 2009; 65:467-487.10.1002/jclp.20593

Stanley EA, Jha AP. Mind fitness and mental armor: Enhancing performance and building warrior resilience. Joint Force Quarterly. 2009; 55:144-151.

Stanton AL, Danoff-Burg S, Cameron CL, Bishop M, Collins CA, Kirk SB, ... Twillman R. Emotionally expressive coping predicts psychological and physical adjustment to breast cancer. Journal of Consulting and Clinical Psychology. 2000; 68:875-882.10.1037/0022-006X.68.5.875 [PubMed: 11068973]

Tooby J, Cosmides L. The past explains the present: Emotional adaptations and the structure of ancestral environments. Ethology \& Sociobiology. 1990; 11:375424.10.1016/0162-3095(90)90017-Z

Tugade MM, Fredrickson BL. Resilient individuals use positive emotions to bounce back from negative emotional experiences. Journal of Personality and Social Psychology. 2004; 86:320333.10.1037/0022-3514.86.2.320 [PubMed: 14769087]

Wadlinger HA, Isaacowitz DM. Positive mood broadens visual attention to positive stimuli. Motivation and Emotion. 2006; 30:87-99.10.1007/s11031-006-9021-1 [PubMed: 20431711]

Waugh CE, Wager TD, Fredrickson BL, Noll DC, Taylor SF. The neural correlates of trait resilience when anticipating and recovering from threat. Social Cognitive and Affective Neuroscience. 2008; 3:322-332.10.1093/scan/nsn024 [PubMed: 19015078]

Zautra A, Smith B, Affleck G, Tennen H. Examinations of chronic pain and affect relationships: Applications of a dynamic model of affect. Journal of Consulting and Clinical Psychology. 2001; 69:786-795.10.1037/0022-006X.69.5.786 [PubMed: 11680555] 


\section{Biographies}

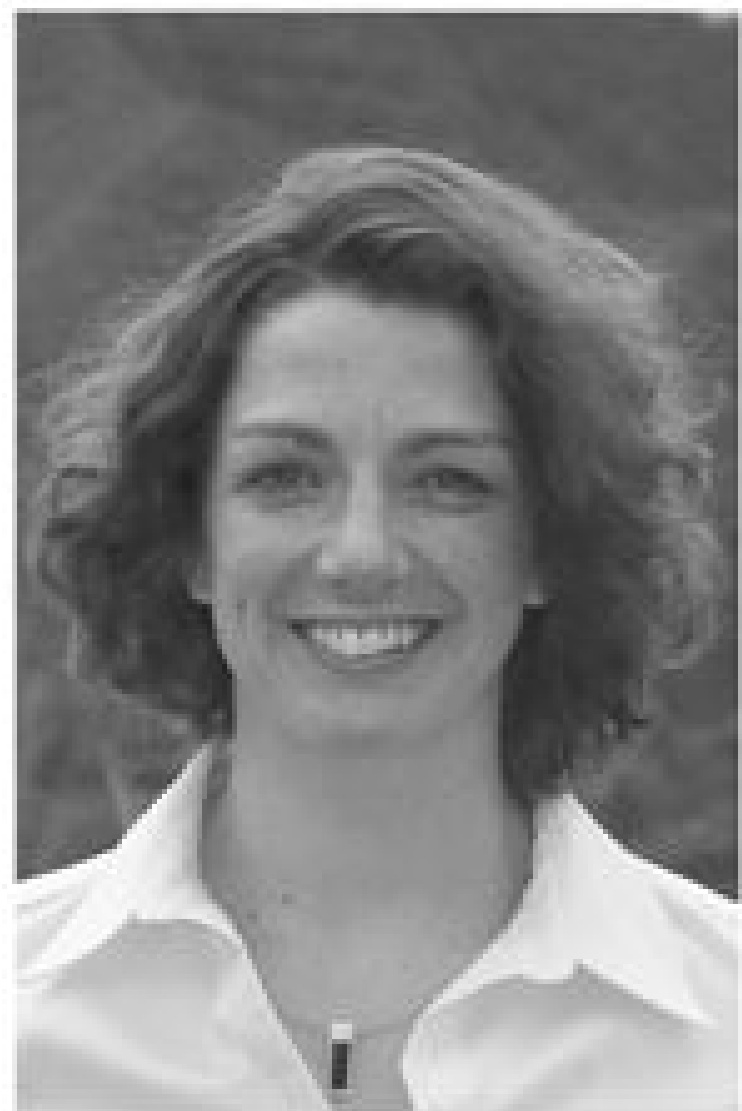

Sara B. Algoe 


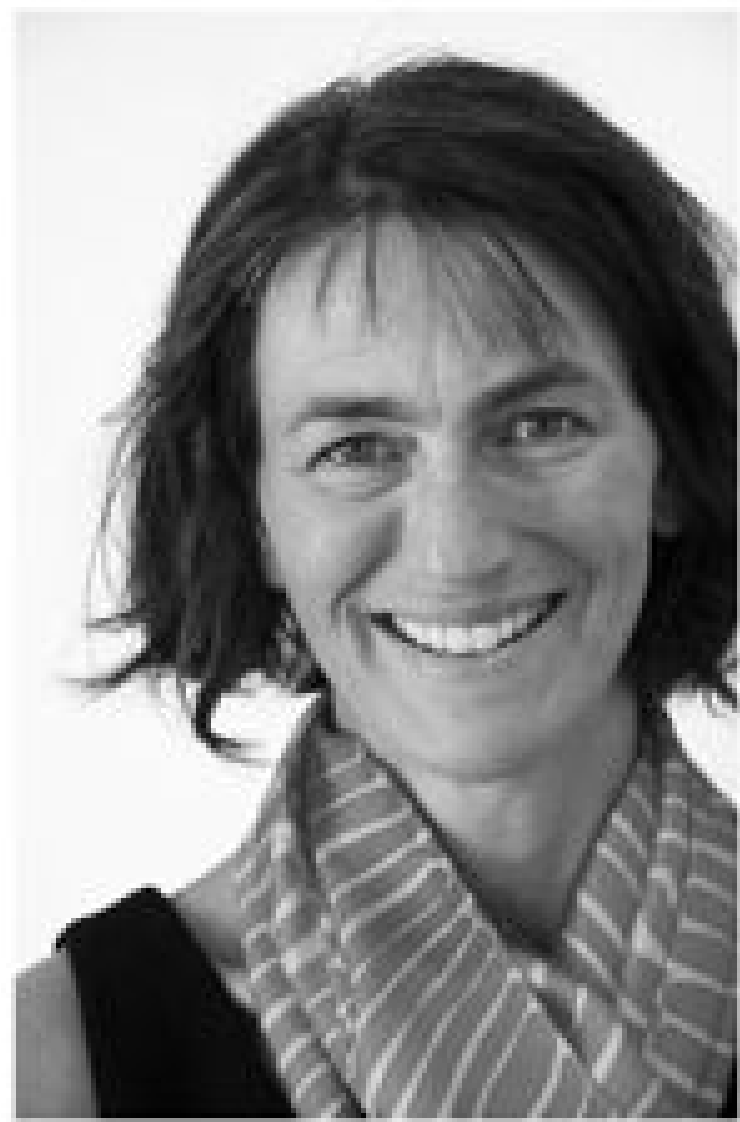

Barbara L. Fredrickson

Photo by Jeff Chappell 